\title{
QUALIDADE NUTRICIONAL DE SEIS HÍBRIDOS DE SORGO COM CAPIM SUDÃO SUBMETIDOS A ÉPOCAS DE PLANTIO E CORTES DISTINTAS
}

\author{
MÁRCIO HENRIQUE RIBEIRO GONTIJO ${ }^{1}$, ANA LUIZA COSTA CRUZ BORGES ${ }^{2}$, LÚCIO \\ CARLOS GONÇALVES ${ }^{2}$, JOSÉ AVELINO SANTOS RODRIGUES ${ }^{3}$, SILAS PRIMOLA GOMES ${ }^{4}$, \\ IRAN BORGES ${ }^{2}$, NORBERTO MÁRIO RODRIGUEZ², MARIANA MAGALHÃES CAMPOS ${ }^{4} \mathrm{e}$ \\ CARLOS GIOVANI PANCOTI ${ }^{5}$
}

\footnotetext{
${ }^{1}$ Mestre em Zootecnia pela Escola de Veterinária da UFMG, Caixa postal 567, CEP: 30123-970- Belo Horizontel $M G$

${ }^{2}$ Professor(a) da Escola de Veterinária da UFMG, Caixa postal 567, CEP: 30123-970- Belo Horizonte/MG

${ }^{3}$ Pesquisador da Embrapa Milho e Sorgo, Sete Lagoas/MG

${ }^{4}$ Doutorando(a) em Zootecnia pela Escola de Veterinária da UFMG; silaspg@ig.com.br; marimcampos@ gmail.com ${ }^{5}$ Médico Veterinário
}

Revista Brasileira de Milho e Sorgo, v.7, n.1, p. 45-56, 2008

\begin{abstract}
RESUMO - Foram avaliados quatro híbridos experimentais (ATF 54 x CMSXS 912, CMSXS 156 x CMSXS 912, CMSXS 157 x CMSXS 912 e CMSXS 210 x CMSXS 912) e duas cultivares comerciais de Sorghum bicolor cv bicolor X Sorghum bicolor cv sudanense (AG2501C e BRS800) quanto ao valor nutritivo: produções de MS digestível (MSD t/ha), digestibilidade in vitro da MS (DIVMS\%), proteína bruta $(\mathrm{PB} \%)$, fibra em detergente neutro (FDN\%), fibra em detergente ácido (FDA\%), fósforo $(\mathrm{P} \%)$ e cálcio $(\mathrm{Ca} \%)$. Os híbridos foram submetidos a três cortes sucessivos e o plantio foi realizado em duas épocas diferentes. O delineamento experimental foi o de blocos ao acaso e a comparação de médias foi efetuada pelo teste de SNK, a 5\% de probabilidade. Os híbridos ATF 54 x CMSXS 912 e AG 2501-C apresentaram valores médios de produção 1,28 t de MSD/ha superiores nas duas épocas de plantio. Ocorreram diferenças entre os híbridos quanto aos teores de $\mathrm{PB}$, com valor médio de $16,33 \%$, Ca com valores entre $0,42 \%$ e $0,49 \%$ e teores de $\mathrm{P}$ com valor médio de $0,26 \%$. O híbrido BRS 800 foi superior $(\mathrm{p}<0,05)$ quanto ao teor médio de $\mathrm{P}(0,28 \%)$, teor médio de PB (17,32\%), sendo semelhante ao híbrido CMSXS 210 x CMSXS 912, que obteve o valor de $16,75 \%$.
\end{abstract}

Palavras-chave: Forragem, regime de corte, Sorghum bicolor, valor nutritivo.

\section{NUTRITIONAL QUALITY OF SIX SORGHUM-SUDANGRASS HYBRIDS SUBMITTED TO DIFFERENT PLANTING TIMES AND THREE SUCCESSIVE CUTS}

\begin{abstract}
Four experimental hybrids (ATF 54 x CMSXS 912, CMSXS 156 x CMSXS 912, CMSXS 157 x CMSXS 912 and CMSXS 210 x CMSXS 912) and two commercial hybrids of Sorghum bicolor cv bicolor X Sorghum bicolor cv sudanense (AG2501C and BRS800) were evaluated in order to determine their nutritional value: digestible dry matter (DDM t/ha), dry matter in vitro digestibility (DMIVD \%), crude
\end{abstract}


protein $(\mathrm{CP} \%)$, neutral detergent fiber (NDF\%), acid detergent fiber (ADF\%), P (\%) and $\mathrm{Ca}(\%)$. The hybrids were submitted to three successive cuts, accomplished at two planting seasons. A randomized blocks experimental design was used and the means were compared by the SNK test $(\mathrm{P}<0.05)$. The ATF53 x CMSXS 912 and AG 2501-C hybrids presented average production values $1.28 \mathrm{t} \mathrm{DDM} / \mathrm{ha}$ higher at the two planting times. The means were higher in the second planting season than in the first, when productions of DDM ( $\mathrm{t} / \mathrm{ha}$ ) indicated a tendency of highest productions at the second planting time. Differences were observed among the hybrids for crude protein (average value $16.33 \%$ ), $\mathrm{Ca}$ (values ranging from $0.42 \%$ to $0.49 \%$ ) and $\mathrm{P}$ (average value $0.26 \%)$. The commercial hybrid BRS800 was superior $(\mathrm{p}<0.05)$ concerning average contents of $\mathrm{P}(0.28 \%)$ and crude protein $(17.32 \%)$, and similar to the experimental hybrid CMSXS 210 x CMSXS 912, for which the obtained value was $16.75 \%$.

Keywords: Forage, Successive cuts, Sorghum bicolor, Nutritional quality.

O sorgo (Sorghum bicolor cv bicolor) é uma forrageira que vem sendo utilizada em diversos países e sob diversas formas. É de grande importância na produção de alimentos, principalmente em regiões onde fatores climáticos limitam a produção de milho. Assim como o sorgo, o capim Sudão (Sorghum bicolor cv sudanense) vegeta bem em climas quentes e com pouca umidade. É uma forrageira anual, com folhas largas e abundantes, que pode chegar a três metros de altura. Possui excelente capacidade de perfilhamento e crescimento rápido, estando pronta para corte dos 75 aos 85 dias (Casela, 1986).

O sorgo forrageiro, utilizado para corte e/ou pastejo, é proveniente de cruzamentos de espécies do gênero Sorghum. Usa-se como macho uma linhagem de capim Sudão (Sorghum bicolor cv sudanense) e como fêmea uma linhagem de sorgo granífero (Sorghum bicolor $\mathrm{cv}$ bicolor). O material resultante desse cruzamento possui alta velocidade de crescimento, grande perfilhamento, elevada resistência à seca, facilidade de manejo para corte e/ou pastejo, além de bom valor nutricional e alta produção por área (Raupp et al., 1999; Rodrigues, 2000).

Nesse contexto, o sorgo de corte (híbridos de capim Sudão com sorgo bicolor), devido as suas características agronômicas e nutricionais, poderá se tornar uma alternativa viável para compor, juntamente com pastagens perenes, forragens conservadas, canaviais, capineiras e rações concentradas, um sistema de alimentação adequado e economicamente viável para rebanhos bovinos de nosso país.

O presente trabalho teve por objetivo determinar o valor nutritivo, assim como a melhor época de plantio e colheita, de quatro híbridos experimentais e dois híbridos comerciais de Sorghum bicolor cv sudanense $\mathrm{x}$ Sorghum bicolor cv bicolor, em três cortes, através da avaliação da produção de MSD (t/ha), da DIVMS (\%), e dos teores de PB\%, FDN $\%$, FDA $\%, \mathrm{P} \%$ e $\mathrm{Ca} \%$. 


\section{Material e Métodos}

Quatro híbridos experimentais e dois híbridos comerciais (testemunhas) de Sorghum bicolor cv bicolor x Sorghum bicolor cv sudanense foram plantados nas dependências da Embrapa de Milho e Sorgo, localizada no Km 45 da MG 424, no município de Sete Lagoas - MG, entre as seguintes coordenadas: 190 de latitude sul e 440 de longitude oeste de Greenwich, com altitude média de $732 \mathrm{~m}$ e precipitação pluviométrica média de $1.340 \mathrm{~mm}$, da qual $86,2 \%$ ocorrem no período chuvoso, de novembro a abril. Segundo a classificação de Köppen, clima do tipo AW (clima de savana, com inverno seco e temperatura média acima de $18^{\circ} \mathrm{C}$ no mês mais frio).

O plantio dos híbridos comerciais (AG2501C e BRS800) e dos híbridos experimentais (ATF 54 x CMSXS 912, CMSXS 156 x CMSXS 912, CMSXS 157 x CMSXS 912 e CMSXS 210 x CMSXS 912) foi realizado em canteiros irrigados, com $5 \mathrm{~m}$ de comprimento e $2,7 \mathrm{~m}$ de largura, contendo quatro linhas, com espaçamento de $0,35 \mathrm{~m}$. Foram utilizadas quatro repetições por híbrido, em duas épocas de plantio diferentes. No planejamento da metodologia experimental do presente trabalho, objetivouse uma padronização do intervalo entre cortes para ambas as épocas de plantio; entretanto, devido a fatores ambientais, não foi possível manter essa padronização durante a execução do experimento. Para facilitar a descrição, os híbridos foram designados pelos números 1,2 , $3,4,5$ e 6 , respectivamente.

O primeiro plantio foi efetuado no dia 22 de agosto, sendo o segundo plantio realizado 13 (treze) dias após o primeiro, no dia quatro de setembro.
Foram feitas adubações no plantio com $300 \mathrm{~kg}$ por hectare da fórmula 04-14-08 (N:P: K) e de cobertura, após cada corte, com 100 $\mathrm{kg}$ de uréia por hectare. Foram realizados três cortes sucessivos em cada época de plantio. $\mathrm{Na}$ primeira época, o primeiro corte ocorreu no dia 11 de outubro (cinqüenta dias após o plantio), o segundo no dia seis de novembro e o terceiro no dia três de dezembro, aos 26 (vinte e seis) e aos 27 (vinte e sete) dias de rebrota, respectivamente. Na segunda época de plantio, o primeiro corte ocorreu no dia 22 de outubro (quarenta e oito dias após o plantio), o segundo corte no dia 23 de novembro e o terceiro no dia três de janeiro, aos 32 (trinta e dois) e 41 (quarenta e um) dias de rebrota, respectivamente.

Realizou-se o corte manual das plantas a cerca de $20 \mathrm{~cm}$ do solo, visando uma simulação de pastejo. Após os cortes, todo material colhido foi pesado em balança de campo tipo dinamômetro e utilizado para a determinação da produção de matéria verde (MV) e de matéria seca (MS) por hectare. Parte do material colhido foi picado, acondicionado em sacos de plástico, identificado e enviado para o laboratório de Nutrição Animal da Escola de Veterinária da UFMG.

As amostras foram pré-secadas em estufa de ventilação forçada, a $65^{\circ} \mathrm{C}$, por 72 horas, e moídas em moinho estacionário, com peneira de $1 \mathrm{~mm}$. Nas amostras pré-secadas foram determinados os teores de $\mathrm{MS}$ a $105^{\circ} \mathrm{C}$, segundo a Association... (CunifF, 1995), A porcentagem de PB foi obtida multiplicandose o teor de nitrogênio obtido pelo método de combustão de Dumas, em analisador Leco FP-528, pelo fator 6,25, e os teores de FDN\% e FDA\%, segundo Silva \& Queiroz (2002). Para os cálculos das produções de 
MSD, foram utilizados os valores de DIVMS determinados pela metodologia de Tilley e Terry (1963).

As análises do teor de P\% foram executadas pelo método colorimétrico, segundo a Association... (Cuniff, 1995). As análises de $\mathrm{Ca}$ foram realizadas em espectrofotômetro de absorção atômica, no Laboratório do Instituto Mineiro de Agropecuária - IMA, segundo Silva \& Queiroz (2002).

O delineamento experimental empregado foi o de blocos ao acaso, sendo quatro repetições, três cortes sucessivos e duas épocas de plantio. Os dados foram avaliados por meio de análise de variância e teste de média, utilizando-se o Sistema de Análises Estatísticas e Genéticas - SAEG (UFV, 2000). Para a comparação das médias, foi empregado o teste SNK (Student Newman Keuls) a 5\% de probabilidade. Também foram estimados os coeficientes de correlação entre as variáveis, através do coeficiente de correlação de Pearson.

\section{Resultados e Discussão}

Para a produção de MSD (Tabela 1), não foi observada diferença $(\mathrm{p}>0,05)$ entre os híbridos, com valores variando entre $0,96 \mathrm{e}$ $1,28 \mathrm{t} / \mathrm{ha}$.

Observa-se que, na época 1, não houve diferença entre híbridos dentro de cada corte, sendo que os híbridos apresentaram produções constantes ao longo dos cortes, demonstrando uma produção estável de MSD na época 1. Já na segunda época, o corte 2 apresentou as maiores produções, com exceção do híbrido 2 , cuja produção de matéria seca digestível foi semelhante nos três cortes. Ainda no corte 2, o híbrido 5 foi semelhante aos híbridos 1 (testemunha), 3, 4 e 6 e superior ao híbrido 2 (testemunha). A época 2 apresentou média de produção superior à época 1.

Algumas estratégias de manejo podem influenciar na capacidade produtiva de híbridos de sorgo de corte e/ou pastejo, podendo levar a aumentos de produtividade por área, que nem sempre são acompanhados por aumento ou manutenção do valor nutricional da forragem obtida. Dessa forma, a determinação da produção de MSD é um parâmetro de avaliação muito importante, pois combina os índices de produção com o valor nutricional (Tomich, 2003). No presente estudo, a produção de MSD apresentou uma correlação positiva de 0,99 $(\mathrm{p}<0,0001)$ com a produção de MS.

A DIVMS é um aspecto relevante na avaliação de alimentos, pois, segundo Silva \& Queiroz (2002), a técnica de DIVMS demonstra ser adequada para se estimar a digestibilidade in vivo, reproduzindo as condições predominantes no rúmen-retículo e apresentando altas correlações com os métodos in vivo.

As médias dos híbridos não diferiram $(\mathrm{p}<0,05)$ quanto a DIVMS, com valor médio de $57,00 \%$ (Tabela 2). Os híbridos apresentaram valores de DIVMS semelhantes dentro de todos os cortes, em ambas as épocas de plantio. $\mathrm{Na}$ época 1 , os híbridos tenderam a apresentar menores valores de DIVMS no terceiro corte, com exceção dos híbridos 3 e 5 , que mantiveram constantes seus coeficientes de digestibilidade ao longo dos cortes, e dos híbridos 1 e 6 , que tiveram os cortes 1 e 3 semelhantes. Na época 2, os híbridos tenderam a apresentar menores valores de DIVMS no corte 2, com exceção dos híbridos 1 e 3, que apresentaram valores de DIVMS semelhantes em todos os cortes, e do híbrido 6, que teve os cortes 2 e 3 semelhantes. As épocas foram semelhantes $(\mathrm{p}>0,05)$ quanto aos valores médios de DIVMS. 
TABELA 1. Produção de matéria seca digestível (MSD), expressa em toneladas por hectare (t/ha), conforme épocas de plantio e cortes realizados

\begin{tabular}{|c|c|c|c|c|c|c|c|}
\hline \multirow{2}{*}{ Híbridos } & \multicolumn{3}{|c|}{ Época 1} & \multicolumn{3}{|c|}{ Época 2} & \multirow[b]{2}{*}{ Médias } \\
\hline & Corte 1 & Corte 2 & Corte 3 & Corte 1 & Corte 2 & Corte 3 & \\
\hline 1 & $0,96 \mathrm{Aa}$ & 0,89Aa & $1,45 \mathrm{Aa}$ & 0,79Abc & 2,20ABa' & $1,41 \mathrm{Ab}$ & $1,28 \mathrm{~A}$ \\
\hline 2 & $1,02 \mathrm{Aa}$ & $0,87 \mathrm{Aa}$ & $1,06 \mathrm{Aa}$ & 0,81Aa' & $1,43 \mathrm{Ba}$ & 1,09Aa' & $1,05 \mathrm{~A}$ \\
\hline 3 & $1,05 \mathrm{Aa}$ & $1,15 \mathrm{Aa}$ & $1,44 \mathrm{Aa}$ & $0,81 \mathrm{Ab}$ & $1,84 \mathrm{ABa}^{\prime}$ & 1,35Aa'b' & $1,27 \mathrm{~A}$ \\
\hline 4 & $0,83 \mathrm{Aa}$ & $0,76 \mathrm{Aa}$ & $0,91 \mathrm{Aa}$ & $0,60 \mathrm{Ab}$ & 2,17ABa' & 0,99Ab' & $1,04 \mathrm{~A}$ \\
\hline 5 & $0,58 \mathrm{Aa}$ & $0,84 \mathrm{Aa}$ & 0,69Aа & 0,48Ac' & 2,63Aa' & $1,16 \mathrm{Ab}$ & $1,06 \mathrm{~A}$ \\
\hline 6 & $0,71 \mathrm{Aa}$ & $0,77 \mathrm{Aa}$ & $1,15 \mathrm{Aa}$ & $0,43 \mathrm{Ab}$ & $2,00 \mathrm{ABa}^{\prime}$ & $0,69 \mathrm{Ab}$ & $0,96 \mathrm{~A}$ \\
\hline Médias & 0,86 & 0,88 & 1,12 & 0,65 & 2,05 & 1,12 & 1,11 \\
\hline Média das épocas & & $0,95 b$ & & & $1,27 \mathrm{a}$ & & - \\
\hline
\end{tabular}

Teste SNK $(\mathrm{p}<0,05), \mathrm{CV}=41,89 \%$. Letras maiúsculas comparam médias na mesma coluna. Letras minúsculas comparam médias na mesma linha na primeira época, e médias das épocas na mesma linha. Letras minúsculas seguidas de apóstrofe comparam médias na mesma linha na segunda época. Híbridos: 1 = AG2501C; 2 = BRS800; 3 = ATF54 x CMSXS 912; 4 = CMSXS 156 x CMSXS 912; 5 = CMSXS 157 x CMSXS 912; 6 = CMSXS 210 x CMSXS 912.

Tomich et al. (2006), avaliando os híbridos de sorgo AG2501CX e BRS800, tiveram valores de DIVMS de 65,9 e 65,5\%, respectivamente.

As tendências de menores valores de DIVMS, em cortes específicos de cada época, podem ser explicadas pela maior altura das plantas nesses cortes, o que propicia uma menor relação folha/haste, inferindo negativamente no valor nutricional da forragem. Verificou-se uma correlação positiva de $0,45(\mathrm{p}<0,0001)$ entre a DIVMS e a relação folha/haste. Verificouse também uma correlação negativa de $-0,42$ $(\mathrm{p}<0,0001)$ entre a DIVMS e os dados de produção de matéria seca e altura das plantas.

Os coeficientes de DIVMS obtidos foram semelhantes aos valores encontrados por Oliveira (1997) e Alkimim Filho (1998). Embora não tenha sido observada superioridade em nenhum dos híbridos avaliados, os valores médios de DIVMS obtidos neste estudo podem ser considerados apropriados para essa forrageira, reafirmando o seu bom valor nutricional.

Houve diferença $(\mathrm{p}<0,05)$ entre as médias dos híbridos para o teor médio de PB (Tabela $3)$. Observa-se que o híbrido 2 (testemunha) foi semelhante ao híbrido 6 , sendo superior aos demais híbridos, que não apresentaram diferenças entre si. Na primeira época de plantio, os híbridos não diferiram dentro dos cortes 2 e 3 , sendo que no corte 1 o híbrido 6 foi semelhante aos híbridos 1, 2 e 3 e superior aos híbridos 4 e 5 .

Comparando-se os cortes, nessa mesma época, os híbridos tenderam a apresentar menores teores protéicos no terceiro corte, com exceção do híbrido 5, que manteve constante seu teor de PB ao longo dos cortes. Na época 2, os híbridos diferiram apenas dentro do corte 2, com destaque ao híbrido 2, que foi semelhante aos híbridos 1, 3 e 6, e superior aos híbridos 4 e 5 . 
TABELA 2. Teores de digestibilidade in vitro da matéria seca (DIVMS), expressos como porcentagem da matéria seca (\%MS), conforme épocas de plantio e cortes realizados

\begin{tabular}{|c|c|c|c|c|c|c|c|}
\hline \multirow{2}{*}{ Híbridos } & \multicolumn{3}{|c|}{ Época 1} & \multicolumn{3}{|c|}{ Época 2} & \multirow[b]{2}{*}{ Médias } \\
\hline & \begin{tabular}{|l|} 
Corte 1 \\
\end{tabular} & Corte 2 & Corte 3 & \begin{tabular}{|l|} 
Corte 1 \\
\end{tabular} & Corte 2 & Corte 3 & \\
\hline 1 & $56,90 \mathrm{Aab}$ & $58,28 \mathrm{Aa}$ & $52,91 \mathrm{Ab}$ & 60,48Aa' & $55,95 \mathrm{Aa}^{\prime}$ & $60,22 \mathrm{Aa}^{\prime}$ & $57,46 \mathrm{~A}$ \\
\hline 2 & $59,89 \mathrm{Aa}$ & $59,99 \mathrm{Aa}$ & $53,18 \mathrm{Ab}$ & 59,54Aa' & $54,24 \mathrm{Ab}$ & $58,65 \mathrm{Aa}^{\prime}$ & $57,58 \mathrm{~A}$ \\
\hline 3 & $55,47 \mathrm{Aa}$ & $57,08 \mathrm{Aa}$ & $52,33 \mathrm{Aa}$ & 59,81Aa' & 56,79Aa' & 55,83Aa' & $56,21 \mathrm{~A}$ \\
\hline 4 & $56,91 \mathrm{Aa}$ & $57,13 \mathrm{Aa}$ & $50,98 \mathrm{Ab}$ & 60,36Аa' & $55,11 \mathrm{Ab}$ & $59,68 \mathrm{Aa}^{\prime}$ & $56,70 \mathrm{~A}$ \\
\hline 5 & $57,97 \mathrm{Aa}$ & $59,55 \mathrm{Aa}$ & $56,54 \mathrm{Aa}$ & 60,71Aa' & $51,03 \mathrm{Ac}$ & $56,26 \mathrm{Ab}$ & $57,01 \mathrm{~A}$ \\
\hline 6 & $55,92 \mathrm{Aab}$ & $58,01 \mathrm{Aa}$ & $51,77 \mathrm{Ab}$ & 60,80Aa' & $55,64 \mathrm{Ab}$ & $59,83 \mathrm{Aa}^{\prime} \mathrm{b}$ & $57,00 \mathrm{~A}$ \\
\hline Médias & 57,18 & 58,34 & 52,95 & 60,28 & 54,80 & 58,41 & 57,00 \\
\hline Média das épocas & & 56,20 & & & 57,90 & & - \\
\hline
\end{tabular}

Teste SNK $(\mathrm{p}<0,05), \mathrm{CV}=5,43 \%$. Letras maiúsculas comparam médias na mesma coluna. Letras minúsculas comparam médias na mesma linha na primeira época, e médias das épocas na mesma linha. Letras minúsculas seguidas de apóstrofe comparam médias na mesma linha na segunda época. Híbridos: $1=$ AG2501C; 2 = BRS800; $3=$ ATF54 x CMSXS 912; 4 = CMSXS 156 x CMSXS 912; 5 = CMSXS 157 x CMSXS 912; $6=$ CMSXS 210 x CMSXS 912.

O estádio de desenvolvimento das plantas de sorgo de corte e/ou pastejo, está diretamente correlacionado com seu valor nutritivo, sendo notada uma queda acentuada do valor protéico da forragem e um aumento significativo das frações fibrosas, com o crescimento e o amadurecimento das plantas. No presente experimento, o teor de PB apresentou correlação negativa de $(r=0,57)(p<0,0001)$ com a porcentagem de FDA.

Os valores de PB observados estão bem acima das necessidades mínimas de um ruminante, pois, segundo Church (1988), uma dieta deve conter pelo menos $7 \%$ de PB para fornecer um aporte de nitrogênio suficiente para uma fermentação efetiva no rúmen. $\mathrm{O}$ valor médio de $16,33 \%$ de PB encontrado está de acordo com diversos trabalhos que têm atribuído bom valor nutricional à forragem produzida por híbridos de sorgo com capim Sudão, sendo relatados altos valores protéicos.
Pereira et al. (1993) encontraram valor médio de 17,4\% de PB para um híbrido de sorgo com capim Sudão cortado aos 64 dias. Tomich (2003) encontrou média de 12,5\% de PB para corte realizado aos 57 dias após o plantio.

Além das variações no estádio vegetativo, fatores como nível de adubação, densidade de plantio e possíveis diferenças entre cultivares são capazes de modificar o conteúdo protéico da forragem de híbridos de sorgo com capim Sudão. Entretanto, como, no presente experimento, houve padronização das medidas de plantio, adubação e demais tratos culturais, os híbridos 2 (testemunha) e 6 (experimental), com maiores teores protéicos médios, destacaram-se nesse parâmetro de avaliação.

A queda da qualidade nutricional das principais forrageiras, no período seco, é um dos principais fatores que tornam a produção animal, em condições de pasto sazonal. Dessa forma, gastos com suplementação alimentar 
TABELA 3.Teores de proteína bruta (PB), expressos como porcentagem da matéria seca (\%MS), conforme épocas de plantio e cortes realizados

\begin{tabular}{|c|c|c|c|c|c|c|c|}
\hline \multirow{2}{*}{ Híbridos } & \multicolumn{3}{|c|}{ Época 1} & \multicolumn{3}{|c|}{ Época 2} & \multirow[b]{2}{*}{ Médias } \\
\hline & Corte 1 & Corte 2 & Corte 3 & Corte 1 & Corte 2 & Corte 3 & \\
\hline 1 & $19,5 \mathrm{ABa}$ & $18,9 \mathrm{Aa}$ & $14,3 \mathrm{Ab}$ & $18,1 \mathrm{Aa}^{\prime}$ & $13,0 \mathrm{ABb}$ & $13,4 \mathrm{Ab}$ & $16,2 \mathrm{~B}$ \\
\hline 2 & $19,7 \mathrm{ABa}$ & $18,4 \mathrm{Aa}$ & $15,6 \mathrm{Ab}$ & 19,8Aa' & $14,9 \mathrm{Ab}$ & $15,5 \mathrm{Ab}$ & $17,3 \mathrm{~A}$ \\
\hline 3 & $19,4 \mathrm{ABa}$ & $18,5 \mathrm{Aa}$ & $13,5 \mathrm{Ab}$ & 17,7Aa' & $13,9 \mathrm{ABb}$ & $12,8 \mathrm{Ab}$ & $15,9 \mathrm{~B}$ \\
\hline 4 & $17,3 \mathrm{Ba}$ & $17,5 \mathrm{Aa}$ & $14,7 \mathrm{Ab}$ & 19,3Аa' & 11,9Bc' & $13,8 \mathrm{Ab}$ & $15,8 \mathrm{~B}$ \\
\hline 5 & $18,1 \mathrm{Ba}$ & $17,0 \mathrm{Aa}$ & $15,9 \mathrm{Aa}$ & 19,1Аa' & 11,9Bb' & $13,7 \mathrm{Ab}$ & $15,9 \mathrm{~B}$ \\
\hline 6 & $21,6 \mathrm{Aa}$ & $17,9 \mathrm{Ab}$ & $14,8 \mathrm{Ac}$ & 19,6Аa' & $13,9 \mathrm{ABb}{ }^{\prime}$ & $13,7 \mathrm{Ab}$ & $16,7 \mathrm{AB}$ \\
\hline Médias & 19,3 & 18,1 & 14,8 & 18,9 & 13,3 & 13,8 & 16,3 \\
\hline Média das épocas & & $17,38 \mathrm{a}$ & & & $17,38 \mathrm{a}$ & & - \\
\hline
\end{tabular}

Teste SNK $(\mathrm{p}<0,05), \mathrm{CV}=8,12 \%$. Letras maiúsculas comparam médias na mesma coluna. Letras minúsculas comparam médias na mesma linha na primeira época, e médias das épocas na mesma linha. Letras minúsculas seguidas de apóstrofe comparam médias na mesma linha na segunda época. Híbridos: 1 = AG2501C; 2 = BRS800; 3 = ATF54 x CMSXS 912; 4 = CMSXS 156 x CMSXS 912; 5 = CMSXS 157 x CMSXS 912; 6 = CMSXS 210 x CMSXS 912.

são responsáveis por grande parte dos custos de produção de bovinos em pasto. Nesse sentido, a utilização de híbridos de sorgo de corte e/ou pastejo torna-se uma boa opção de forrageira para ser utilizada em períodos de escassez de alimentos volumosos, com boa oferta de forragem, com adequado valor nutricional, como visto neste trabalho, valor médio de $16,33 \%$ de $\mathrm{PB}$ na matéria seca. Esse valor é superior aos valores de PB dos principais recursos forrageiros utilizados como alternativas às pastagens instaladas, como cana-de-açúcar, capim-elefante e silagens de milho e sorgo, segundo as Tabelas Brasileiras de Composição de Alimentos para Bovinos (Valadares Filho et al., 2002).

A determinação das frações fibrosas é muito importante na caracterização de forragens quanto ao seu valor nutritivo. As frações FDN, FDA e lignina são negativamente correlacionadas com a digestibilidade e, consequientemente, com o valor energético das forragens. Mais especificamente, o conteúdo de FDN relaciona-se principalmente às limitações de consumo, sendo as frações de FDA e lignina mais associadas às reduções nos coeficientes de digestibilidade (Van Soest, 1994). Dessa maneira, a seleção de híbridos com menores proporções desses componentes, não existindo outros fatores envolvidos, seria vantajosa. De maneira geral, no presente experimento, os híbridos foram semelhantes quanto aos teores de carboidratos estruturais, havendo apenas diferenças entre as médias de épocas, não sendo observada superioridade de nenhum dos híbridos avaliados para esse parâmetro de seleção.

Não houve diferença $(p>0,05)$ entre as médias dos híbridos estudados, sendo que os valores apresentaram pequena amplitude de variação, com média de 54,85\% de FDN (Tabela 4).Tomich (2003) encontrou valor 
médio de $67,7 \%$ de FDN para vinte e cinco híbridos de sorgo com capim Sudão, porém as plantas estavam em estádio vegetativo mais avançado, aos 57 dias após o plantio, que foi feito no verão.

Os híbridos não apresentaram diferenças $(\mathrm{p}>0,05)$ dentro dos cortes em ambas as épocas de plantio. Na época 2, os híbridos mantiveram constantes seus teores de FDN ao longo dos cortes, com exceção do híbrido 6, que apresentou maiores teores de FDN no corte 3. Já na época 1, os híbrido 1 (testemunha) manteve constante seus valores de FDN ao longo dos cortes, os híbridos 4 e 5 apresentaram menores valores no corte 3 , os híbridos 3 e 6 apresentaram o corte 2 semelhante ao corte $1 \mathrm{e}$ superior ao corte 3 , e o híbrido 2 (testemunha) apresentou maiores teores de FDN no corte 2. A época 2 apresentou média superior $(\mathrm{p}<0,05)$ à época 1 , diferença esta que pode ser explicada pela maior altura das plantas na época 2, visto que, segundo Van Soest (1994), os teores de FDN de uma forragem aumentam durante seu desenvolvimento e são maiores no colmo do que nas folhas.

Comparando-se as médias dos híbridos, observa-se que esses foram semelhantes $(\mathrm{p}>0,05)$ quanto aos seus teores médios de FDA, com média geral de 31,04\% de FDA (Tabela 5). Esse valor é bem próximo aos $30,40 \%$ de FDA encontrados por Simili et al. (2002) para o híbrido comercial AG2501C, utilizado neste experimento como testemunha, cortado com cerca de $1,00 \mathrm{~m}$ de altura.

$\mathrm{Na}$ época 1, não houve diferença entre híbridos dentro dos cortes. Já na época 2, os híbridos apresentaram diferenças $(\mathrm{p}<0,05)$ dentro do corte 3 , com menor valor encontrado para o híbrido 4 e o maior valor para o híbrido 3. O híbrido 3 foi semelhante aos híbridos 2 , 5 e 6 e o híbrido 4 semelhante aos híbridos 1 , 2 e 5 . Na época 1 , os híbridos apresentaram

TABELA 4. Teores de fibra em detergente neutro (FDN), expressos como porcentagem da matéria seca (\%MS), conforme épocas de plantio e cortes realizados

\begin{tabular}{|c|c|c|c|c|c|c|c|}
\hline \multirow{2}{*}{ Híbridos } & \multicolumn{3}{|c|}{ Época 1} & \multicolumn{3}{|c|}{ Época 2} & \multirow[b]{2}{*}{ Médias } \\
\hline & Corte 1 & Corte 2 & Corte 3 & Corte 1 & Corte 2 & Corte 3 & \\
\hline 1 & $54,08 \mathrm{Aa}$ & $56,91 \mathrm{Aa}$ & $53,15 \mathrm{Aa}$ & $54,38 \mathrm{Aa}$ & 55,38Aa' & $55,38 \mathrm{Aa}^{\prime}$ & $54,95 \mathrm{~A}$ \\
\hline 2 & $52,93 \mathrm{Ab}$ & $58,33 \mathrm{Aa}$ & $50,47 \mathrm{Ab}$ & $53,70 \mathrm{Aa}$ & $57,35 \mathrm{Aa}^{\prime}$ & $57,35 \mathrm{Aa}^{\prime}$ & $54,81 \mathrm{~A}$ \\
\hline 3 & $54,43 \mathrm{Aab}$ & $58,01 \mathrm{Aa}$ & $52,03 \mathrm{Ab}$ & $54,96 \mathrm{Aa}$ & 55,51Aa' & 55,51Aa' & $55,55 \mathrm{~A}$ \\
\hline 4 & $53,96 \mathrm{Aa}$ & $54,92 \mathrm{Aa}$ & $49,35 \mathrm{Ab}$ & $55,49 \mathrm{Aa}$ & $55,73 \mathrm{Aa}$ & $55,73 \mathrm{Aa}^{\prime}$ & $54,67 \mathrm{~A}$ \\
\hline 5 & $55,45 \mathrm{Aa}$ & $56,72 \mathrm{Aa}$ & $51,06 \mathrm{Ab}$ & $52,40 \mathrm{Aa}$ & 55,11Aa' & $55,11 \mathrm{Aa}$ & $54,47 \mathrm{~A}$ \\
\hline 6 & $53,40 \mathrm{Aab}$ & $56,10 \mathrm{Aa}$ & $51,49 \mathrm{Ab}$ & $53,69 \mathrm{Ab}$ & $54,71 \mathrm{Ab}$ & $54,71 \mathrm{Ab}$ & $54,66 \mathrm{~A}$ \\
\hline Médias & 54,04 & 56,83 & 51,26 & 54,10 & 55,63 & 57,23 & 54,85 \\
\hline Média das & & $54,04 \mathrm{~b}$ & & & $55,65 \mathrm{a}$ & & - \\
\hline
\end{tabular}

Teste SNK ( $\mathrm{p}<0,05), \mathrm{CV}=4,67 \%$. Letras maiúsculas comparam médias na mesma coluna. Letras minúsculas comparam médias na mesma linha na primeira época, e médias das épocas na mesma linha. Letras minúsculas seguidas de apóstrofe comparam médias na mesma linha na segunda época. Híbridos: $1=$ AG2501C; 2 = BRS800; 3 = ATF54 x CMSXS 912; 4 = CMSXS 156 x CMSXS 912; 5 = CMSXS 157 x CMSXS 912; $6=$ CMSXS 210 x CMSXS 912. 
TABELA 5. Teores de fibra em detergente ácido (FDA), expressos como porcentagem da matéria seca $(\% \mathrm{MS})$, conforme épocas de plantio e cortes realizados

\begin{tabular}{|c|c|c|c|c|c|c|c|}
\hline \multirow{2}{*}{ Híbridos } & \multicolumn{3}{|c|}{ Época 1} & \multicolumn{3}{|c|}{ Época 2} & \multirow[b]{2}{*}{ Médias } \\
\hline & Corte 1 & Corte 2 & Corte 3 & Corte 1 & Corte 2 & Corte 3 & \\
\hline 1 & $30,23 \mathrm{Aab}$ & $28,62 \mathrm{Ab}$ & $32,52 \mathrm{Aa}$ & $30,81 \mathrm{Ab}$ & $34,83 \mathrm{Aa}^{\prime}$ & 30,55BCb' & $31,26 \mathrm{~A}$ \\
\hline 2 & $28,20 \mathrm{Aa}$ & $30,23 \mathrm{Aa}$ & $28,50 \mathrm{Aa}$ & $29,36 \mathrm{Ab}$ & 36,80Aa' & $32,08 \mathrm{ABCb}$ & $30,86 \mathrm{~A}$ \\
\hline 3 & $29,85 \mathrm{Aa}$ & $27,68 \mathrm{Aa}$ & $31,14 \mathrm{Aa}$ & $31,44 \mathrm{Ab}$ & 33,51Aa'b' & 35,32Aa' & $31,32 \mathrm{~A}$ \\
\hline 4 & $30,40 \mathrm{Aa}$ & $28,67 \mathrm{Aa}$ & $30,43 \mathrm{Aa}$ & $31,28 \mathrm{Ab}$ & 34,92Aa' & $28,64 \mathrm{Cb}$ & $30,72 \mathrm{~A}$ \\
\hline 5 & $28,83 \mathrm{Aa}$ & $28,44 \mathrm{Aa}$ & $30,13 \mathrm{Aa}$ & $29,75 \mathrm{Ab}$ & 36,99Аa' & $31,61 \mathrm{ABCb}$ & $30,96 \mathrm{~A}$ \\
\hline 6 & $28,68 \mathrm{Aa}$ & $28,84 \mathrm{Aa}$ & $30,90 \mathrm{Aa}$ & $30,38 \mathrm{Ab}$ & $34,23 \mathrm{Aa}$ & 33,51ABa' & $31,09 \mathrm{~A}$ \\
\hline Médias & 29,37 & 28,75 & 30,60 & 30,50 & 35,21 & 31,95 & 31,04 \\
\hline Média das épocas & & $29,51 b$ & & & $29,51 b$ & & - \\
\hline
\end{tabular}

Teste SNK $(\mathrm{p}<0,05), \mathrm{CV}=6,87 \%$. Letras maiúsculas comparam médias na mesma coluna. Letras minúsculas comparam médias na mesma linha na primeira época, e médias das épocas na mesma linha. Letras minúsculas seguidas de apóstrofe comparam médias na mesma linha na segunda época. Híbridos: 1 = AG2501C; 2 = BRS800; 3 = ATF54 x CMSXS 912; 4 = CMSXS 156 x CMSXS 912; 5 = CMSXS 157 x CMSXS 912; 6 = CMSXS 210 x CMSXS 912.

tendência a manter a porcentagem de FDA ao longo dos cortes, com exceção do híbrido 1, que apresentou maiores valores de FDA no corte 3 , sendo semelhante ao corte 1 e superior ao corte 2 , que não diferiu do corte 1 . Na época 2, houve tendência a maiores valores de FDA no segundo corte, com exceção dos híbridos 3 e 6 , que tiveram o corte 3 semelhante ao corte 2 , o que pode estar associado a uma maior altura das plantas nesse corte. Assim como para o teor de FDN, a época 2 apresentou média superior à época $1(\mathrm{p}<0,05)$, para o teor de FDA. O teor de FDA apresentou correlação positiva de 0,57 $(\mathrm{p}<0,0001)$ com a altura das plantas.

Observa-se que houve diferença $(\mathrm{p}<0,05)$ entre as médias dos híbridos para a porcentagem de $\mathrm{P}$ (Tabela 6). Nota-se que o híbrido 2, utilizado como testemunha, foi superior aos demais híbridos, que foram semelhantes entre si. Em ambas as épocas de plantio, os híbridos foram semelhantes dentro de cada corte. $\mathrm{Na}$ época 1 , todos os híbridos mantiveram iguais seus teores de $\mathrm{P}$ ao longo dos cortes. $\mathrm{Na}$ segunda época de plantio, apenas os híbridos 2, 3 e 6 apresentaram constância no teor de $\mathrm{P}$ ao longo dos cortes, não sendo observada essa constância para os híbridos 1, 4 e 5, Não se observou diferença entre as médias das épocas.

$\mathrm{O}$ teor médio de $\mathrm{P}$ encontrado no presente experimento $(0,26 \%)$ é considerado bastante alto, quando comparado aos valores apresentados pelas Tabelas Brasileiras de Composição de Alimentos para Bovinos (Valadares Filho et al., 2002) para outras gramíneas utililizadas para corte e/ou pastejo. Pereira et al. (1993) encontraram valor médio de 0,29\% de P para um híbrido de sorgo com capim Sudão.

Verifica-se que houve diferença $(\mathrm{p}<0,05)$ entre as médias dos híbridos (Tabela 7), sendo o híbrido 4 semelhante aos híbridos 1, 2, e 5, e superior aos híbridos 3 e 6. Esses últimos foram semelhantes entre si e aos híbridos 1, 
TABELA 6. Teores de fósforo (P), expressos como porcentagem da matéria seca (\%MS), conforme épocas de plantio e cortes realizados

\begin{tabular}{|c|c|c|c|c|c|c|c|}
\hline \multirow{2}{*}{ Híbridos } & \multicolumn{3}{|c|}{ Época 1} & \multicolumn{3}{|c|}{ Época 2} & \multirow[b]{2}{*}{ Médias } \\
\hline & Corte 1 & Corte 2 & \begin{tabular}{|l|l|} 
Corte 3 \\
\end{tabular} & Corte 1 & Corte 2 & Corte 3 & \\
\hline 1 & $0,24 \mathrm{Aa}$ & $0,26 \mathrm{Aa}$ & $0,25 \mathrm{Aa}$ & 0,29Aa' & $0,23 \mathrm{Ab}$ & 0,26Aa'b' & $0,25 \mathrm{~B}$ \\
\hline 2 & $0,29 \mathrm{Aa}$ & $0,26 \mathrm{Aa}$ & $0,29 \mathrm{Aa}$ & 0,30Aa' & 0,27Aa' & 0,29Aa' & $0,28 \mathrm{~A}$ \\
\hline 3 & $0,25 \mathrm{Aa}$ & $0,27 \mathrm{Aa}$ & $0,25 \mathrm{Aa}$ & 0,26Aa' & 0,24Aa' & 0,24Aa' & $0,25 \mathrm{~B}$ \\
\hline 4 & $0,26 \mathrm{Aa}$ & $0,25 \mathrm{Aa}$ & $0,25 \mathrm{Aa}$ & 0,27Aa' & $0,21 \mathrm{Ab}$ & $0,25 \mathrm{Aa}^{\prime} \mathrm{b}$ ' & $0,25 \mathrm{~B}$ \\
\hline 5 & $0,25 \mathrm{Aa}$ & $0,24 \mathrm{Aa}$ & $0,26 \mathrm{Aa}$ & 0,29Aa' & $0,22 \mathrm{Ab}$ & 0,27Aa' & $0,25 \mathrm{~B}$ \\
\hline 6 & $0,28 \mathrm{Aa}$ & $0,23 \mathrm{Aa}$ & $0,25 \mathrm{Aa}$ & $0,25 \mathrm{Aa}^{\prime}$ & 0,23Aa' & $0,25 \mathrm{Aa}^{\prime}$ & $0,25 \mathrm{~B}$ \\
\hline Médias & 0,26 & 0,25 & 0,26 & 0,28 & 0,23 & 0,26 & 0,26 \\
\hline Média das épocas & & $0,26 \mathrm{a}$ & & & $0,26 \mathrm{a}$ & & - \\
\hline
\end{tabular}

Teste SNK ( $<<0,05), C V=12,31 \%$. Letras maiúsculas comparam médias na mesma coluna. Letras minúsculas comparam médias na mesma linha na primeira época, e médias das épocas na mesma linha. Letras minúsculas seguidas de apóstrofe comparam médias na mesma linha na segunda época. Híbridos: $1=$ AG2501C; 2 = BRS800; 3 = ATF54 x CMSXS 912; 4 = CMSXS 156 x CMSXS 912; 5 = CMSXS 157 x CMSXS 912; $6=$ CMSXS 210 x CMSXS 912.

2 e 5. Na primeira época de plantio, houve diferença entre híbridos no corte 3 , em que o híbrido 5 foi semelhante aos híbridos $1,3,4,5$ e 6 e superior ao híbrido 2 (testemunha). Ainda no corte 3, os híbridos 3, 4 e 6, por sua vez, foram semelhantes entre si e ao híbrido 2.

Comparando-se os cortes, os teores de Ca dos híbridos 2, 3, 4 e 5 foram similares nos três cortes. Já os híbridos 1 (testemunha) e 6 apresentaram valores superiores nos cortes 3 e 1 , sendo que este último foi superior ao corte 2. Na época 2, os híbridos não diferiram dentro de cada corte. Comparando-se os cortes, os híbridos 1, 4 e 6 mantiveram constantes seus teores de $\mathrm{Ca}$ ao longo dos cortes, o que não ocorreu para os híbridos 2, 3 e 5. A média da época 1 foi superior $(\mathrm{p}<0,05)$ à da época 2 .

$\mathrm{O}$ valor médio de $0,45 \%$ de $\mathrm{Ca}$ encontrado neste trabalho é ligeiramente inferior ao relatado por Pereira et al. (1993), que, avaliando o híbrido de sorgo com capim Sudão AG-2501C, encontraram valor médio de $0,52 \%$.
A proporção e a composição da fração mineral de um vegetal, dentro dos limites estabelecidos por sua constituição genética, são controladas por fatores ambientais, dos quais o suprimento de nutrientes é, geralmente, de importância primordial. Dessa forma, as diferenças encontradas entre híbridos e entre épocas para a composição mineral podem ser explicadas pela variabilidade genética existente entre híbridos, uma vez que se buscou, na metodologia experimental do presente trabalho, controlar o efeito de fertilidade dos canteiros experimentais. O híbrido 2 (testemunha) se destacou, apresentando o maior teor de P. Sabese que essa é uma característica nutricional importante, pois o baixo teor de $\mathrm{P}$ encontrado para a maioria das gramíneas tropicais utilizadas em sistemas de pastejo em nosso país constitui, segundo McDowell. (1983), a principal deficiência mineral de bovinos em pasto nos trópicos. Vale ressaltar que a suplementação do elemento mineral $\mathrm{P}$ é a de maior ônus, 
TABELA 7. Teores de cálcio (Ca), expressos como porcentagem da matéria seca (\%MS), conforme épocas de plantio e cortes realizados

\begin{tabular}{|c|c|c|c|c|c|c|c|}
\hline \multirow{2}{*}{ Híbridos } & \multicolumn{3}{|c|}{ Época 1} & \multicolumn{3}{|c|}{ Época 2} & \multirow[b]{2}{*}{ Médias } \\
\hline & Corte 1 & Corte 2 & Corte 3 & Corte 1 & Corte 2 & Corte 3 & \\
\hline 1 & $0,48 \mathrm{Aab}$ & $0,44 \mathrm{Ab}$ & $0,56 \mathrm{Aa}$ & 0,42Aa' & 0,36Аa' & 0,44Aa' & $0,45 \mathrm{AB}$ \\
\hline 2 & $0,48 \mathrm{Aa}$ & $0,46 \mathrm{Aa}$ & $0,43 \mathrm{Ba}$ & 0,47Aa'b' & 0,39Ab' & 0,50Aa' & $0,45 \mathrm{AB}$ \\
\hline 3 & $0,44 \mathrm{Aa}$ & $0,46 \mathrm{Aa}$ & $0,46 \mathrm{ABa}$ & 0,49Aa' & $0,36 \mathrm{Ab}$ & 0,43Aa'b' & $0,44 \mathrm{~B}$ \\
\hline 4 & $0,55 \mathrm{Aa}$ & 0,49Aa & $0,53 \mathrm{ABa}$ & $0,45 \mathrm{Aa}^{\prime}$ & $0,42 \mathrm{Aa}$ & 0,51Aa' & $0,49 \mathrm{~A}$ \\
\hline 5 & $0,51 \mathrm{Aa}$ & 0,46 Aa & $0,56 \mathrm{Aa}$ & $0,47 \mathrm{Aa}^{\prime}$ & $0,35 \mathrm{Ab}$ & 0,48Aa' & $0,47 \mathrm{AB}$ \\
\hline 6 & $0,45 \mathrm{Aab}$ & $0,39 \mathrm{Ab}$ & $0,49 \mathrm{ABa}$ & $0,40 \mathrm{Aa}^{\prime}$ & 0,37Aa' & 0,44Aa' & $0,42 \mathrm{~B}$ \\
\hline Médias & 0,49 & 0,45 & 0,49 & 0,45 & 0,38 & 0,47 & 0,45 \\
\hline Média das épocas & & $0,48 \mathrm{a}$ & & & $0,43 b$ & & - \\
\hline
\end{tabular}

Teste SNK ( $<<0,05), C V=13,47 \%$. Letras maiúsculas comparam médias na mesma coluna. Letras minúsculas comparam médias na mesma linha na primeira época, e médias das épocas na mesma linha. Letras minúsculas seguidas de apóstrofe comparam médias na mesma linha na segunda época. Híbridos: $1=$ AG2501C; 2 = BRS800; 3 = ATF54 x CMSXS 912; 4 = CMSXS 156 x CMSXS 912; 5 = CMSXS 157 x CMSXS 912; 6 = CMSXS 210 x CMSXS 912.

devido ao alto valor de mercado das fontes inorgânicas desse mineral, mostrando, dessa forma, mais um benefício econômico do bom valor nutricional dos híbridos de sorgo com capim Sudão.

\section{Conclusões}

Os híbridos experimentais de sorgo com capim Sudão ATF 54 x CMSXS 912 e CMSXS 210 x CMSXS 912 avaliados apresentam composição bromatológica e coeficientes de DIVMS semelhantes aos híbridos comerciais. Dessa maneira, esses híbridos devem continuar a ser utilizados no programa de melhoramento de Sorghum bicolor cv bicolor X Sorghum bicolor cv sudanense.

\section{Literatura Citada}

ALKIMIM FILHO, J. F. Valor nutritivo de silagens de híbridos de Sorghum bicolor $\mathbf{x}$
Sorghum sudanense submetidos a diferentes tempos de pré-secagem. 1998. 95 f. Dissertação (Mestrado) - Escola de Veterinária, Universidade Federal de Minas Gerais, Belo Horizonte.

CASELA, C.R.; BORGONOVI, R. A.; SCHAFFERT, R. E.; SANTOS, F. G. Cultivares de sorgo. Informe Agropecuário, Belo Horizonte, v. 12, n. 144, p. 40-43, 1986.

CHURCH, D. C. The ruminant animal digestive physiology and nutrition. New Jersey: Prentice Hall, 1988. 564 p.

CUNIFF, P. (Ed.). Official methods of analysis of AOAC International. 16. ed. Gaithersburg: AOAC International, 1995. 2000 p.

McDOWELL, L. R., CONRAD, J. H., ELLIS, C. L., LOOSLI, J. K. Minerals for grazing ruminants in tropical regions. Gainesville: University Florida, 1983. 86 p. 
OLIVEIRA, C. L. M. Avaliação nutricional de silagens de híbridos de Sorghum bicolor $\boldsymbol{x}$ Sorghum Sudanense. 1997. 77 f. Dissertação (Mestrado) - Escola de Veterinária, Universidade Federal de Minas Gerais, Belo Horizonte.

PEREIRA, O. G.; OBEID, J. A.; GOMIDE, J. A. Produtividade e valor nutritivo de aveia (Avena sativa), milheto (Pennisetum americanum L.), e de um híbrido de Sorghum bicolor $x S$. sudanense. Revista Brasileira de Zootecnia, Viçosa, v. 22, n. 1, p. 22-31, 1993.

RAUPP, A. A. A.; BRANCÃO, N.; FRANCO, J. C. B. Ensaio Sul Riograndense de sorgo forrageiro para corte e pastejo 1998/99. Capão do Leão, RS. In: REUNIÃO TÉCNICA ANUAL DO MILHO, 44.; REUNIÃO TÉCNICA DO SORGO, 27., 1999, Porto Alegre. Anais... Porto Alegre: FEPAGRO: EMATER-RS: FECOAGRO, 1999.

RODRIGUES, J. A. S. Utilização de forragem fresca de sorgo (Sorghum bicolor $x$ Sorghum sudanense) sob condições de corte e pastejo. In: In: SIMPÓSIO DE FORRAGICULTURA E PASTAGENS, 1., 2000. Lavras. Temas em evidência. Lavras: UFLA, 2000. p.179-201. Editado por Antonio Ricardo Evangelista, Thiago Fernandes Bernardes, Eleuza Clarete Junqueira de Sales.

SILVA, D. J.; QUEIROZ, A. C. Análise de alimentos: métodos químicos e biológicos. Viçosa: UFV, 2002. 235 p.

SIMILI, F. F.; REIS, R. A.; MOREIRA, A. L.; MALHEIROS, E. B. ; PEDREIRA, M. S.; SEIXAS, P. F. Avaliação da produção de forragem de sorgo Sudão e milheto semeados em diferentes épocas. In: REUNIÃO ANUALDA SOCIEDADE BRASILEIRA DE ZOOTECNIA, 39., 2002, Recife. Anais... Recife: SBZ, p. 1-5,2002.

TILLEY, J. M. A.; TERRY, R. A. A two-stage technique for the "in vitro" digestion of forage crops. Journal of the British Grassland Society, Oxford, v.18, n. 2, p.104-111, 1963.

TOMICH, T. R.; TOMICH, R. G. P.; GONÇALVES, L. C.; BORGES, I.; RODRIGUES, J. A. S. Valor nutricional de híbridos de sorgo com capimsudão em comparação ao de outros volumosos utilizados no período de baixa disponibilidade das pastagens. Arquivo Brasileiro de Medicina Veterinaria e Zootecnia, Belo Horizonte, v. 58, n. 6, p. 1249-1252, 2006.

TOMICH, T. R. Potencial forrageiro de híbridos de sorgo com capim Sudão (Sorghum bicolor $x$ Sorghum sudanense) avaliados em regime de corte. 2003. $88 \mathrm{f}$. Tese (Doutorado) - Escola de Veterinária, Universidade Federal de Minas Gerais, Belo Horizonte.

UNIVERSIDADE FEDERAL DE VIÇOSA. SAEG - Sistema de análises estatísticas e genéticas (manual do usuário). Versão 8.0. Viçosa, MG, 2000.142 p.

VALADARES FILHO, S. C.; ROCHA JUNIOR., V. R.; CAPPELLE, E. R. Tabelas brasileiras de composição de alimentos para bovinos. Viçosa: UFV; DZO; DPI, 2002. 297 p.

VAN SOEST, P. J. Nutritional ecology of the ruminant. 2 ed. Ithaca: Cornell University Press, 1994. 476 p. 